\title{
Evidence on Adrenaline Use in Resuscitation and Its Relevance to Newborn Infants: A Non-Systematic Review
}

\author{
Merlin Pinto ${ }^{a, b}$ Anne Lee Solevåga, ${ }^{a, d}$ Megan O'Reilly ${ }^{a, c}$ Khalid Aziz ${ }^{a, b}$ \\ Po-Yin Cheung ${ }^{a, b}$ Georg M. Schmölzera,b \\ ${ }^{a}$ Centre for the Studies of Asphyxia and Resuscitation, Neonatal Research Unit, Royal Alexandra Hospital, and \\ Departments of ${ }^{b}$ Pediatrics and ${ }^{C}$ Physiology, University of Alberta, Edmonton, Alta., Canada; ${ }^{\mathrm{d} D e p a r t m e n t}$ of \\ Pediatric and Adolescent Medicine, Akershus University Hospital, Lørenskog, Norway
}

\section{Key Words}

Infants · Newborn · Delivery room - Neonatal resuscitation ·

Adrenaline $\cdot$ Chest compression

\begin{abstract}
Aim: Guidelines for newborn resuscitation state that if the heart rate does not increase despite adequate ventilation and chest compressions, adrenaline administration should be considered. However, controversy exists around the safety and effectiveness of adrenaline in newborn resuscitation. The aim of this review was to summarise a selection of the current knowledge about adrenaline during resuscitation and evaluate its relevance to newborn infants. Methods: A search in PubMed, Embase, and Google Scholar until September 1, 2015, using search terms including adrenaline/ epinephrine, cardiopulmonary resuscitation, death, severe brain injury, necrotizing enterocolitis, bronchopulmonary dysplasia, and adrenaline versus vasopressin/placebo. $\boldsymbol{R e}$ sults: Adult data indicate that adrenaline improves the return of spontaneous circulation (ROSC) but not survival to hospital discharge. Newborn animal studies reported that adrenaline might be needed to achieve ROSC. Intravenous administration (10-30 $\mu \mathrm{g} / \mathrm{kg})$ is recommended; however, if there is no intravenous access, a higher endotracheal dose
\end{abstract}

๑) 2016 S. Karger AG, Basel
$(50-100 \mu \mathrm{g} / \mathrm{kg})$ is needed. The safety and effectiveness of intraosseous adrenaline remain undetermined. Early and frequent dosing does not seem to be beneficial. In fact, negative hemodynamic effects have been observed, especially with doses $\geq 30 \mu \mathrm{g} / \mathrm{kg}$ intravenously. Little is known about adrenaline in birth asphyxia and in preterm infants, but observations indicate that hemodynamics and neurological outcomes may be impaired by adrenaline administration in these conditions. However, a causal relationship between adrenaline administration and outcomes cannot be established from the few available retrospective studies. Alternative vasoconstrictors have been investigated, but the evidence is scarce. Conclusion: More research is needed on the benefits and risks of adrenaline in asphyxia-induced bradycardia or cardiac arrest during perinatal transition.

(c) 2016 S. Karger AG, Basel

\section{Introduction}

Chest compressions (CC) and adrenaline (epinephrine) are infrequently used in neonatal resuscitation [13]. Extensive resuscitation, defined as $\mathrm{CC}$ with or without adrenaline administration occurs in $6-10 \%$ of very and extremely low birth weight infants [4]. Less is known

\section{KARGER}

E-Mail karger@karger.com

www.karger.com/neo
Georg M. Schmölzer, MD, PhD

Centre for the Studies of Asphyxia and Resuscitation

Neonatal Research Unit, Royal Alexandra Hospital

10240 Kingsway Avenue NW, Edmonton, AB T5H 3V9 (Canada)

E-Mail georg.schmoelzer@me.com 
about the incidence in term infants, but Perlman and Risser [3] reported a total incidence of CC and/or adrenaline of $0.12 \%$ in term and preterm infants. O'Donnell et al. [5] reported in 1998 a mortality rate after cardiopulmonary resuscitation (CPR) including adrenaline administration of $70 \%$ in infants $\leq 29$ weeks of gestation and $33 \%$ in term infants. Overall, $79 \%$ of the infants $\leq 29$ weeks of gestation either died or survived with severe disability [5]. Although mortality rates have changed over the last couple of decades, particularly in term asphyxiated infants after the introduction of therapeutic hypothermia [6], the rates of mortality and neurodevelopmental impairment remain high $[7,8]$. Strategies to optimize $\mathrm{CC}$ and medication administration in the delivery room (DR) are needed. Bradycardia immediately after birth is usually the result of inadequate lung aeration [3], profound hypoxemia [9], or (more rarely) hypovolemia from blood loss. Establishing adequate ventilation is therefore the cornerstone intervention in DR resuscitation of bradycardic infants [10]. International resuscitation guidelines recommend CC only if the heart rate remains $<60$ / min despite adequate ventilation [10]. If the heart rate does not increase despite effective ventilation and CC administration, adrenaline administration should be considered [10]. However, the use of adrenaline during neonatal resuscitation is largely based on evidence from adult literature [11] and animal studies [12]. In asphyxiated newborn infants with fluid-filled lungs and open vascular shunts, there is limited evidence regarding both the effectiveness and safety of adrenaline [13]. Current controversies surrounding the use of adrenaline in neonatal CPR include (1) the effects of adrenaline versus placebo or no adrenaline [14], (2) optimal dose [15], (3) route of administration [16, 17], (4) timing of administration [18, 19], (5) alternative vasopressors [11], and (6) use in preterm infants [20]. The aim of this review is to summarise a selection of available evidence regarding the use of adrenaline during resuscitation and its relevance to asphyxiated newborn infants.

\section{Methods}

A non-systematic literature search was conducted in PubMed, Embase, and Google scholar until September 1, 2015 by three of the authors (M.P., A.L.S., and G.M.S.), using search terms including adrenaline/epinephrine, CPR, death, neurodevelopmental impairment, necrotizing enterocolitis (NEC), bronchopulmonary dysplasia, and adrenaline versus vasopressin/placebo. We included studies not restricted to the newborn population. First we limited the broad search to randomized controlled trials. Due to a paucity of identified randomized clinical trials, we included case series, cohort studies, case-control studies, and even case reports. The evidence base about adrenaline's mechanisms of action is mainly derived from animal studies. Thus, animal studies that we considered relevant were also included. Results were limited to adrenaline use in CPR, and thus excluded adrenaline used for hypotension in the neonatal intensive care unit. Still, the number of references identified through the search was far too large for a systematic evidence evaluation to be completed. We made a selection of references among the identified studies and reports driven by a pragmatic approach that partly reflects our own opinion and expertise in the field of neonatal resuscitation. Since our approach was not systematic, we did not limit our search to specific end points. For the same reason, a systematic evaluation of the quality of the evidence (e.g. AGREE or GRADE) was not performed.

\section{Results}

No randomized controlled trials are available investigating mortality and morbidity associated with adrenaline administration during CPR of newborn infants of various gestational ages (GA).

\section{Mechanisms of Action}

\section{Human Studies}

Adults. Coronary perfusion pressure (CPP) is a predictor of return of spontaneous circulation (ROSC) in human adults [21], and therapies that improve CPP, including adrenaline [22], increase the probability of ROSC [21].

Newborn Term or Preterm Infants. No studies were identified.

\section{Animal Studies}

Adult Animals. Through its effect on $\beta$-adrenergic receptors, adrenaline increases the conduction velocity and thus the heart rate (chronotropy), as well as contractility (inotropy). In theory, adrenaline is beneficial in CPR due to the combined effects on $\alpha$ - and $\beta$-receptors. However, experimentalstudiesin dogshave shown that $\alpha$-stimulation, but not $\beta$-stimulation, is required for successful resuscitation $[23,24]$. Little is known about the maturation and distribution of $\alpha$ - and $\beta$-adrenergic receptors in term and preterm infants, compared to adults and different animal species [25]. In addition, respiratory [26] and metabolic [27] acidosis may inhibit the favourable haemodynamic responses to adrenaline. There is in fact increasing evidence that the increased myocardial oxygen demand caused by $\beta$-adrenergic stimulation can be detrimental when adrenaline is used in a state of persisting hypoxia [28].
38

Neonatology 2017;111:37-44 DOI: $10.1159 / 000447960$
Pinto/Solevåg/O'Reilly/Aziz/Cheung/ Schmölzer 
Through its effect on $\alpha$-adrenergic receptors, adrenaline mediates peripheral vasoconstriction while forward flow is generated with CC [29], thus elevating the aortic pressure and CPP in pigs [30]. CPP is determined by the aortic to right atrial pressure gradient during the relaxation ('diastolic') phase of CPR [31, 32]. CPP correlates with myocardial blood flow in dogs [31], and is a positive predictor of ROSC in pigs [30]. Through the same mechanism, adrenaline increases cerebral blood flow in dogs [31]. In addition, $\alpha$-agonism may counteract CPR-induced collapse of the carotid arteries resulting from elevated intrathoracic pressures, further optimizing cerebral blood flow [31, 33]. Michael et al. [31] demonstrated in dogs with ventricular fibrillation (VF) cardiac arrest that as a result of adrenaline-induced reversal of carotid artery collapse, blood flow increased more to the caudal than rostral regions of the brain, while decreasing blood flow to extracerebral vascular beds.

In adult animals, the effects of adrenaline are not limited to the period of CPR, but may also affect myocardial function after ROSC $[34,35]$. Adrenaline, especially in high and repeated doses, has potential adverse effects including (1) prolonged hypertension and tachycardia [35, 36], (2) impairment of the blood brain barrier [37], (3) increased myocardial oxygen demand and oxidative stress [38] with negative post-resuscitation effects on cardiac function [34, 39], and (4) myocardial ischemia and necrosis [40].

Newborn Animals. In neonatal animals, adrenaline might cause imbalance of neurotransmitters and their receptors including $\gamma$-aminobutyric acid [41], serotonin [42], acetylcholine [43], and dopamine [44]. However, beneficial effects including increased cerebral blood flow in infant pigs [32] and subsequently cerebral oxygen uptake [32] have also been demonstrated.

\section{Areas of Controversy}

Effects of Adrenaline versus Placebo or No Adrenaline Human Studies

Adults. In a double-blind placebo-controlled trial of 534 out-of-hospital cardiac arrests (OHCA), ROSC occurred in $22(8.4 \%)$ patients receiving placebo and 64 $(23.5 \%)$ receiving adrenaline $(\mathrm{OR}=3.4$; $95 \% \mathrm{CI}: 2.0-5.6)$ [14]. Survival to hospital discharge occurred in 5 (1.9\%) and $11(4.0 \%)$ patients receiving placebo and adrenaline, respectively (OR $=2.2 ; 95 \%$ CI: 0.7-6.3) [14]. Similarly, Olasveengen et al. [45] randomised 851 patients with OHCA to either intravenous (IV) medication adminis- tration versus no IV medication administration. Adrenaline was used in the majority of events. Other medications included atropine and amiodarone. Patients with IV medication administration had higher ROSC rates upon hospital admission $(\mathrm{p}<0.001)$. However, survival to hospital discharge $(\mathrm{p}=0.61)$ and survival with favourable neurological outcome $(\mathrm{p}=0.45)$ was similar between the groups [45].

Newborn Term or Preterm Infants. No studies were identified.

\section{Animal Studies}

Adult Animals. Using adult rats with asphyxia-induced cardiac arrest, McCaul et al. [46] found that adrenaline administration improved mean aortic pressure, $\mathrm{CPP}$, cerebral perfusion pressure, and ROSC, but with the drawback of increased mortality $(\mathrm{p}<0.05)$, hypertension $(\mathrm{p}<0.001)$, and tachycardia $(\mathrm{p}=0.004)$ compared to saline controls.

Newborn Term Animals. McNamara et al. [11] showed that $14 \%$ of asphyxiated piglets with cardiac arrest can achieve ROSC without vasopressors. However, also using asphyxiated piglets with cardiac arrest, Solevåg et al. [47, 48 ] reported that CC alone did not generate a sufficient diastolic blood pressure as a proxy for CPP. Almost all animals required adrenaline to achieve $\operatorname{ROSC}[47,48]$. This is further supported by Sobotka et al. [49], who reported that administration of adrenaline was a prerequisite for achieving ROSC in a transitional near-term lamb model of asphyxia-induced bradycardia and hypotension.

Newborn Preterm Animals. No studies were identified. Studies in adult humans, as well as in adult and newborn term animals, suggest that adrenaline improves ROSC both in adult OHCA and in experimental asphyxia-induced cardiac arrest. However, in asphyxia, there might be a trade-off with higher mortality after adrenaline administration.

\section{Optimal Dose}

The 2015 International Liaison Committee on Resuscitation (ILCOR) treatment recommendations did not review the use of adrenaline during neonatal resuscitation [10]. However, in 2010 the ILCOR recommended a dose of $10-30 \mu \mathrm{g} / \mathrm{kg} \mathrm{IV}$, and advised against higher IV doses as they might be potentially harmful [50].

Human Studies

Adults. No relevant studies were identified. 
Older Children. Perondi et al. [51] randomised 68 children (mean age $\sim 6$ years of age) to either 10 versus 100 $\mu \mathrm{g} / \mathrm{kg}$ for the $2 \mathrm{nd}$ dose of adrenaline after initial failure to one dose of $10 \mu \mathrm{g} / \mathrm{kg}$. Although ROSC rates were similar, none of the children receiving high-dose adrenaline survived the first $24 \mathrm{~h}$ versus a $20.6 \%$ survival among those receiving the lower dose. Similarly, Patterson et al. [52] compared 10 versus $100 \mu \mathrm{g} / \mathrm{kg}$ followed by a second dose of $200 \mu \mathrm{g} / \mathrm{kg}$ if needed in paediatric patients with OHCA. No advantage of higher adrenaline doses in terms of ROSC, short- and long-term survival, or neurological outcome were observed. In fact, survival was markedly reduced in the high-dose group when the arrest was precipitated by asphyxia.

Newborn Term or Preterm Infants. No studies were identified.

\section{Animal Studies}

Adult Animals. In the rat study by McCaul et al. [46], adrenaline administration resulted in a dose-related reduction in left ventricular end-diastolic diameter $(\mathrm{p}<$ 0.05 ), dose-related tachycardia and hypertension, and increased mortality (33\% in $10 \mu \mathrm{g} / \mathrm{kg}$ and $72.8 \%$ in $30 \mu \mathrm{g} /$ $\mathrm{kg})$ compared to normal saline $(0 \%)(\mathrm{p}<0.05)$. Serum cardiac troponin-I at $2 \mathrm{~h}$ after resuscitation was higher in the animals that received $30 \mu \mathrm{g} / \mathrm{kg}$ adrenaline compared to saline controls.

Newborn Animals. No studies were identified.

These data suggest no advantage of high dose adrenaline, but aggravated hypertension, tachycardia, and increased mortality in asphyxia-induced cardiac arrest. Unfortunately, no randomised studies in newborn infants were identified and are urgently needed.

\section{Route of Administration}

ILCOR states that if IV access is not available and adrenaline has to be administered, the endotracheal (ET) route using $50-100 \mu \mathrm{g} / \mathrm{kg}$ should be used. This recommendation is based on a small number of non-neonatal animal studies [53-56] and human case series [5, 16, 57].

Human Studies

Adults. No studies were identified.

Newborn Term or Preterm Infants. An ET adrenaline dose of $50-100 \mu \mathrm{g} / \mathrm{kg}$ might achieve a similar effect as an IV dose of $10 \mu \mathrm{g} / \mathrm{kg}[50,58]$. However, clinical observations indicate that only $32 \%$ of infants who received the first adrenaline dose via the ET route achieved ROSC [16]. Of the 30 infants who did not achieve ROSC, 77\% achieved ROSC after IV adrenaline administration. These results might be explained by dilution of adrenaline in the fluid-filled alveoli of depressed newborn infants in the DR $[59,60]$. Also, elevated pulmonary artery pressures in the presence of a patent ductus arteriosus can potentially result in blood from the right ventricle bypassing the lungs and thus limiting the absorption of adrenaline from the lungs $[59,60]$.

Case reports indicate that intramuscular administration of adrenaline in newborn infants may cause significant tissue damage at the injection site, even at a 1:10,000 concentration and a dose of $20 \mu \mathrm{g} / \mathrm{kg}$ [61].

Ellemunter et al. [62] reported 27 cases of term $(n=$ 7 ) and preterm ( $n=20$, of which 7 were $\leq 26$ weeks of gestation) use of intraosseous access for resuscitation. In addition to catecholamines, infusions included volume expanders, sodium bicarbonate, calcium gluconate, analgesics, sedatives, muscle relaxants, glucose, blood products, and antibiotics. No major complications were noted.

Animals

Adult Animals. In pigs with VF, $100 \mu \mathrm{g} / \mathrm{kg}$ ET adrenaline was compared to $10 \mu \mathrm{g} / \mathrm{kg}$ and control (no adrenaline) [53]. $100 \mu \mathrm{g} / \mathrm{kg}$ resulted in a higher increase in plasma adrenaline levels, but not a higher blood pressure compared to $10 \mu \mathrm{g} / \mathrm{kg}$ adrenaline and control [53]. Roberts et al. [54] demonstrated in dogs that after ET adrenaline administration, the maximum blood concentration of adrenaline was approximately one tenth that achieved with an equal IV dosage.

Newborn Animals. Kleinman et al. [63] compared administration of $10 \mu \mathrm{g} / \mathrm{kg}$ adrenaline into either the femoral vein, the right atrium, or ET during CPR in newborn pigs with VF cardiac arrest. ET administration resulted in lower plasma adrenaline concentrations; however, the number of animals achieving ROSC was similar between all groups.

Mauch et al. [17] demonstrated that $100 \mu \mathrm{g} / \mathrm{kg}$ intramuscular adrenaline resulted in similar ROSC and survival compared to $10 \mu \mathrm{g} / \mathrm{kg}$ IV adrenaline in infant piglets with ropivacaine-induced pulseless electrical activity or asystole.

\section{Simulation Studies}

Abe et al. [64] performed a simulation study and reported that the intraosseous access was faster and subjectively easier than the umbilical venous access when inexperienced providers were assessed. However, due to the limited evidence, intraosseous lines are not recommended in newborn resuscitation [7].
Pinto/Solevåg/O'Reilly/Aziz/Cheung/ Schmölzer 
In summary, the rate of ROSC seems to be higher with IV versus ET adrenaline administration in newborn infants. Taking into account the unique transitional physiology, there is both clinical and theoretical rationale to suggest that ET adrenaline is less effective than IV administration in DR CPR. Until more data on the safety and effectiveness of intramuscular adrenaline is available, this route of administration is not recommended.

\section{Timing of Administration}

Currently, administration of adrenaline is not recommended unless the heart rate remains $<60 /$ min despite adequate ventilation and CC [50].

Human Studies

Adults. Warren et al. [18] reviewed almost 21,000 adults with in-hospital cardiac arrests and found that an adrenaline average dosing period (i.e. 'the time between the first adrenaline dose and the resuscitation end point, divided by the total number of adrenaline doses received subsequent to the first adrenaline dose' [18]) of 9-10 min/ dose improved survival compared to the recommended 4-5 $\mathrm{min} /$ dose [18].

Newborn Term or Preterm Infants. No studies were identified.

\section{Animal studies}

Adult Animals. No relevant studies were identified.

Newborn Animals. Linner et al. [19] studied early adrenaline administration in newborn piglets with severe asphyxia and bradycardia. Adrenaline was administered prior to CC, which did not improve ROSC or cerebral regional oxygen saturation when compared to placebo.

These studies suggest that neither early nor frequent adrenaline dosing is beneficial.

\section{Alternative Vasopressors or Adrenaline in \\ Combination with $\beta$-Antagonists}

Human Studies

Adults. Endogenous vasopressin levels have been found to be higher in successfully resuscitated patients than in patients who died [65]. Thus, it has been suggested that vasopressin might be beneficial in CPR. Vasopressin (40 IU) was superior to adrenaline (1 mg) in OHCA patients with asystole [66]. However, no benefit of adding vasopressin (40 IU) to IV adrenaline (1 mg) during OHCA has been demonstrated in randomized controlled trials [67].

Newborn Term or Preterm Infants. No studies were identified.

Adrenaline Use in Resuscitation and Its

Relevance to Newborn Infants
Animals

Adult Animals. Vasopressin is a potent vasoconstrictor and might be used as an alternative to or addition to adrenaline during CPR $[11,68,69]$. Studies in adult pigs and rats have reported that either $\beta$-receptor antagonism (e.g. esmolol [34]) or selective $\alpha$-agonism (e.g. phenylephrine $[29,34]$ ) potentially reduce the detrimental side effects of adrenaline.

In rats with VF, $30 \mu \mathrm{g} / \mathrm{kg}$ adrenaline and $300 \mu \mathrm{g} / \mathrm{kg}$ phenylephrine had similar haemodynamic effects during CPR; however, post-ROSC myocardial dysfunction was increased and the duration of survival after ROSC was decreased after adrenaline compared to phenylephrine administration [34]. $30 \mu \mathrm{g} / \mathrm{kg}$ adrenaline combined with $300 \mu \mathrm{g} / \mathrm{kg}$ esmolol resulted in similar effects as phenylephrine, with improved myocardial function and survival after ROSC compared to adrenaline alone [34].

Newborn Animals. A continuous infusion of phenylephrine $\left(40^{15}\right.$ or $\left.20^{70} \mu \mathrm{g} / \mathrm{kg} / \mathrm{min}\right)$ had similar effects as adrenaline in infant pigs [15] and dogs [70] with VF cardiac arrest.

No clinical studies are available about vasopressin, esmolol, or phenylephrine in paediatric or neonatal CPR. Thus, alternative vasopressors to adrenaline cannot be recommended in DR CPR.

\section{Preterm Infants}

Studies about the benefits and risks of adrenaline during DR CPR of preterm infants are completely lacking. However, large cohort studies have shown that extensive DR CPR is associated with intraventricular haemorrhage grades $3-4$ in extremely preterm infants $[1,2,71]$ potentially caused by blood pressure fluctuations aggravated by adrenaline administration [72]. Also, there is a theoretical possibility that adrenaline, through its vasoconstrictive effects, may cause major organ injury including renal failure and NEC in vulnerable individuals $[73,74]$.

Frontanes et al. [71] compared the outcomes of 80 very low birth weight infants (i.e. $<1,500 \mathrm{~g}$ ) who required extensive DR CPR to $221 \mathrm{GA}$ - and birth weight-matched infants without CPR. Not surprisingly, infants receiving CPR interventions had significantly lower survival (26 vs. $43 \%$, $\mathrm{p}<0.01$ ) and survival without brain injury (17 vs. $32 \%$, $\mathrm{p}=0.011)$, as well as higher rates of respiratory distress syndrome $(\mathrm{p}<0.01)$ and NEC (20 vs. 9\%, $\mathrm{p}=0.018)$ [71].

In 13,758 extremely preterm infants (GA $22+0$ to $27+$ 6 weeks), Handley et al. [1] found that DR CPR was associated with early-onset sepsis, intraventricular haemorrhage grades 3-4, postnatal steroids, and death before hospital discharge, but not with death in the first $12 \mathrm{~h}$ of life, pneu-

Neonatology 2017;111:37-44

DOI: $10.1159 / 000447960$ 
mothorax, patent ductus arteriosus, cystic periventricular leukomalacia, NEC, or bronchopulmonary dysplasia.

Extensive DR CPR is therefore associated with lower survival rates with or without neurological impairment, especially in low birth weight infants. However, limitations of most of the retrospective studies include that they do not distinguish between DR CPR with CC alone or CC + adrenaline, or between infants receiving CPR interventions and those who truly need CC and/or adrenaline [3]. Another very important limitation is that, if used correctly, adrenaline is given to the most compromised infants who are likely to have the worst outcomes irrespective of the adrenaline administration.

\section{Knowledge Gaps}

Current knowledge on the use of adrenaline in newborn infants is limited to retrospective studies, as well as extrapolations from animals and adult humans. Most animal studies of newborn resuscitation including adrenaline have been performed in post-transitional animals. The unique transitional physiology with fluid-filled lungs and elevated pulmonary vascular pressure, as well as open fetal shunts, make studies in animals during the perinatal transition warranted. There are significant physiological differences in different GA groups, and therapies including adrenaline are likely to have GA-specific effects and side effects. Guidelines for neonatal resuscitation do not differentiate between different GA groups for CC and adrenaline. The knowledge about physiological effects with resulting risks and benefits in preterm infants is completely lacking. Performing randomised controlled trials remains difficult, mainly due to the low incidence of infants requiring DR CC with or without adrenaline, as well as ethical concerns. The vast majority of studies in animals and humans were in VF arrest, not asphyxia. Currently, there is a lack of data about benefits and risks, dose, and timing of adrenaline administration in asphyxia-induced bradycardia. Data to assess the interactions of adrenaline with $\alpha$ - and $\beta$-adrenergic receptors during or after CC in different GA is needed. Lastly studies should examine potential alternative vasoconstrictor drugs to be administered during neonatal CPR.

\section{Conclusion}

VF animal models have shown that adrenaline increases aortic pressure, coronary perfusion, and cerebral perfusion pressure. However, these favourable effects might be attenuated and/or counterbalanced in newborn infants due to (1) asphyxia with a combined respiratory and metabolic acidosis, (2) potentially different expression and sensitivity of subtypes of adrenergic receptors, and (3) vulnerability of preterm infants to fluctuations in blood pressure. In newborns, only retrospective data is available about the outcomes after adrenaline administration during CPR. A causal relationship between CPR with or without adrenaline and outcomes cannot be established in the retrospective studies, but extensive CPR with or without adrenaline administration seems to be associated with increased risk of intraventricular haemorrhage in preterm infants. In compromised infants of all gestations, care should be taken to optimize the assisted ventilation before initiating CC and/or administering adrenaline. More research is needed in appropriate animal models and if possible in clinical trials. While acknowledging the ethical challenges of performing CPR research in newborn infants, as well as the infrequent occurrence of DR CPR interventions, we propose the following important research questions to be further investigated:

1 In newborn infants requiring extensive resuscitation, what is the relationship between the extent of resuscitation and the survival rate and long-term outcomes of survivors?

2 In asphyxiated newborn infants, does adrenaline administration prior to initiation of CC reduce time to ROSC compared to adrenaline administration after $30 \mathrm{~s}$ of CC?

3 In asphyxiated newborn infants, do other vasopressors (e.g. vasopressin) during DR CPR improve the outcomes including time to ROSC, mortality, and/or morbidity compared to adrenaline?

4 In preterm infants, does adrenaline administration during DR CPR affect the outcome including time to ROSC, mortality, and/or morbidity compared to placebo?

\section{Acknowledgement}

A.L.S. is supported by the Canadian Institutes of Health Research (operating grant MOP-CIA-299111 to P.-Y.C. and travel award to A.L.S.) and the South-Eastern Norway Regional Health Authority. M.O. is supported by a Molly Towell Perinatal Research Foundation Fellowship. G.M.S. is a recipient of the Heart and Stroke Foundation/University of Alberta Professorship of Neonatal Resuscitation and Heart and Stroke Foundation Canada Research Scholar.

\section{Disclosure Statement}

The authors declare no conflicts of interest.
Pinto/Solevåg/O'Reilly/Aziz/Cheung/ Schmölzer 


\section{References}

1 Handley SC, Sun Y, Wyckoff MH, Lee HC: Outcomes of extremely preterm infants after delivery room cardiopulmonary resuscitation in a population-based cohort. J Perinatol 2015;35:379-383

2 Wyckoff MH, Salhab WA, Heyne RJ, Kendrick DE, Stoll BJ, Laptook AR, et al: Outcome of extremely low birth weight infants who received delivery room cardiopulmonary resuscitation. J Pediatr 2012;160:239-244.e2.

3 Perlman JM, Risser R: Cardiopulmonary resuscitation in the delivery room. Associated clinical events. Arch Pediatr Adolesc Med 1995; 149:20-25.

4 Shah PS: Extensive cardiopulmonary resuscitation for VLBW and ELBW infants: a systematic review and meta-analyses. J Perinatol 2009;29:655-661.

5 O’Donnell AI, Gray PH, Rogers YM: Mortality and neurodevelopmental outcome for infants receiving adrenaline in neonatal resuscitation. J Paediatr Child Health 1998;34:551556.

6 Jacobs SE, Berg M, Hunt R, Tarnow-Mordi WO, Inder TE, Davis PG: Cooling for newborns with hypoxic ischaemic encephalopathy. Cochrane Database Syst Rev 2013; 1:CD003311.

7 Kattwinkel J, Niermeyer S, Nadkarni V, Tibballs J, Phillips B, Zideman D, et al: ILCOR advisory statement: resuscitation of the newly born infant: an advisory statement from the pediatric working group of the International Liaison Committee on Resuscitation. Circulation 1999;99:1927-1938.

8 Richmond S, Wyllie J: European Resuscitation Council Guidelines for Resuscitation 2010 Section 7. Resuscitation of babies at birth. Resuscitation 2010;81:1389-1399.

9 Kapadia V, Wyckoff MH: Chest compressions for bradycardia or asystole in neonates. Clin Perinatol 2012;39:833-842.

10 Perlman JM, Wyllie J, Kattwinkel J, Wyckoff MH, Aziz K, Guinsburg R, et al: Part 7: Neonatal resuscitation: 2015 International Consensus on Cardiopulmonary Resuscitation and Emergency Cardiovascular Care Science with Treatment Recommendations. Circulation 2015;132:S204-S241.

11 McNamara PJ, Engelberts D, Finelli M, Adeli K, Kavanagh BP: Vasopressin improves survival compared with epinephrine in a neonatal piglet model of asphyxial cardiac arrest. Pediatr Res 2014;75:738-748.

12 Barber CA, Wyckoff MH: Neonatal Cardiac Compressions Following Asystole from Asphyxia: Beneficial or Futile? Pediatric Academic Societies Meeting. Toronto, Pediatric Academic Societies, 2007, E-PAS2007:7932.

13 Wyckoff MH, Perlman J, Niermeyer S: Medications during resuscitation - what is the evidence? Semin Neonatol 2001;6:251-259.

14 Jacobs IG, Finn JC, Jelinek GA, Oxer HF, Thompson PL: Effect of adrenaline on survival in out-of-hospital cardiac arrest: a ran- domised double-blind placebo-controlled trial. Resuscitation 2011;82:1138-1143.

15 Berkowitz ID, Gervais H, Schleien CL, Koehler RC, Dean JM, Traystman RJ: Epinephrine dosage effects on cerebral and myocardial blood flow in an infant swine model of cardiopulmonary resuscitation. Anesthesiology 1991;75:1041-1050.

16 Barber CA, Wyckoff MH: Use and efficacy of endotracheal versus intravenous epinephrine during neonatal cardiopulmonary resuscitation in the delivery room. Pediatrics 2006;118: 1028-1034.

17 Mauch J, Ringer SK, Spielmann N, Weiss M: Intravenous versus intramuscular epinephrine administration during cardiopulmonary resuscitation - a pilot study in piglets. Paediatr Anaesth 2013;23:906-912.

18 Warren SA, Huszti E, Bradley SM, Chan PS, Bryson CL, Fitzpatrick AL, et al: Adrenaline (epinephrine) dosing period and survival after in-hospital cardiac arrest: A retrospective review of prospectively collected data. Resuscitation 2014;85:350-358.

19 Linner R, Werner O, Perez-de-Sa V, CunhaGoncalves D: Early adrenaline administration does not improve circulatory recovery during resuscitation from severe asphyxia in newborn piglets. Resuscitation 2012;83:12981303.

20 Moore GP, Daboval T, Coughlin KW: Chest compressions and epinephrine during resuscitation of infants born at the border of viability: yes, no or maybe? Paediatr Child Health 2011;16:87-90.

21 Paradis NA, Martin GB, Rivers EP, Goetting MG, Appleton TJ, Feingold M, et al: Coronary perfusion pressure and the return of spontaneous circulation in human cardiopulmonary resuscitation. JAMA 1990;263:1106-1113.

22 Gonzalez ER, Ornato JP, Garnett AR, Levine RL, Young DS, Racht EM: Dose-dependent vasopressor response to epinephrine during CPR in human beings. Ann Emerg Med 1989; 18:920-926.

23 Otto CW, Yakaitis RW, Blitt CD: Mechanism of action of epinephrine in resuscitation from asphyxial arrest. Crit Care Med 1981;9:321324.

24 Redding JS, Pearson JW: Evaluation of drugs for cardiac resuscitation. Anesthesiology 1963;24:203-207.

25 Zaritsky A, Chernow B: Use of catecholamines in pediatrics. J Pediatr 1984;105:341-350.

26 Idris AH, Becker LB, Fuerst RS, Wenzel V, Rush WJ, Melker RJ, et al: Effect of ventilation on resuscitation in an animal model of cardiac arrest. Circulation 1994;90:3063-3069.

27 Preziosi MP, Roig JC, Hargrove N, Burchfield DJ: Metabolic acidemia with hypoxia attenuates the hemodynamic responses to epinephrine during resuscitation in lambs. Crit Care Med 1993;21:1901-1907.

28 Ornato JP: Optimal vasopressor drug therapy during resuscitation. Crit Care 2008;12:123.
29 Brown CG, Werman HA, Davis EA, Katz S, Hamlin RL: The effect of high-dose phenylephrine versus epinephrine on regional cerebral blood flow during CPR. Ann Emerg Med 1987;16:743-748.

30 Burnett AM, Segal N, Salzman JG, McKnite MS, Frascone RJ: Potential negative effects of epinephrine on carotid blood flow and ETCO2 during active compression-decompression CPR utilizing an impedance threshold device. Resuscitation 2012;83:1021-1024.

31 Michael JR, Guerci AD, Koehler RC, Shi AY, Tsitlik J, Chandra N, et al: Mechanisms by which epinephrine augments cerebral and myocardial perfusion during cardiopulmonary resuscitation in dogs. Circulation 1984; 69:822-835.

32 Schleien CL, Dean JM, Koehler RC, Michael JR, Chantarojanasiri T, Traystman R, et al: Effect of epinephrine on cerebral and myocardial perfusion in an infant animal preparation of cardiopulmonary resuscitation. Circulation 1986;73:809-817.

33 Yin FC, Cohen JM, Tsitlik J, Zola B, Weisfeldt ML: Role of carotid artery resistance to collapse during high-intrathoracic-pressure CPR. Am J Physiol 1982;243:H259-H267.

34 Tang W, Weil MH, Sun S, Noc M, Yang L, Gazmuri RJ: Epinephrine increases the severity of postresuscitation myocardial dysfunction. Circulation 1995;92:3089-3093.

35 Berg RA, Otto CW, Kern KB, Sanders AB, Hilwig RW, Hansen KK, et al: High-dose epinephrine results in greater early mortality after resuscitation from prolonged cardiac arrest in pigs: a prospective, randomized study. Crit Care Med 1994;22:282-290.

36 Hilwig RW, Kern KB, Berg RA, Sanders AB, Otto CW, Ewy GA: Catecholamines in cardiac arrest: role of alpha agonists, beta-adrenergic blockers and high-dose epinephrine. Resuscitation 2000;47:203-208.

37 Dahlgren N, Rosen I, Sakabe T, Siesjo BK: Cerebral functional, metabolic and circulatory effects of intravenous infusion of adrenaline in the rat. Brain Res 1980;184:143-152.

38 Kapadia VS, Wyckoff MH: Drugs during delivery room resuscitation - what, when and why? Semin Fetal Neonatal Med 2013;18: 357-361.

39 Hornchen U, Lussi C, Schuttler J: Potential risks of high-dose epinephrine for resuscitation from ventricular fibrillation in a porcine model. J Cardiothorac Vasc Anesth 1993;7:184-187.

40 Todd GL, Baroldi G, Pieper GM, Clayton FC, Eliot RS: Experimental catecholamine-induced myocardial necrosis. I. Morphology, quantification and regional distribution of acute contraction band lesions. J Mol Cell Cardiol 1985;17:317-338.

41 Anju TR, Abraham PM, Antony S, Paulose CS: Alterations in cortical GABAB receptors in neonatal rats exposed to hypoxic stress: role of glucose, oxygen, and epinephrine resuscitation. Mol Cell Biochem 2010;343:1-11. 
42 Anju TR, Korah PK, Jayanarayanan S, Paulose CS: Enhanced brain stem $5 \mathrm{HT}_{2} \mathrm{~A}$ receptor function under neonatal hypoxic insult: role of glucose, oxygen, and epinephrine resuscitation. Mol Cell Biochem 2011;354:151160.

43 Chathu F, Krishnakumar A, Paulose CS: Acetylcholine esterase activity and behavioral response in hypoxia induced neonatal rats: effect of glucose, oxygen and epinephrine supplementation. Brain Cogn 2008;68:59-66.

44 Joseph B, Nandhu MS, Paulose CS: Dopamine $\mathrm{D} 1$ and $\mathrm{D} 2$ receptor functional down regulation in the cerebellum of hypoxic neonatal rats: neuroprotective role of glucose and oxygen, epinephrine resuscitation. Pharmacol Res 2010;61:136-141.

45 Olasveengen TM, Sunde K, Brunborg C, Thowsen J, Steen PA, Wik L: Intravenous drug administration during out-of-hospital cardiac arrest: a randomized trial. JAMA 2009;302:2222-2229.

46 McCaul CL, McNamara PJ, Engelberts D, Wilson GJ, Romaschin A, Redington AN, et al: Epinephrine increases mortality after brief asphyxial cardiac arrest in an in vivo rat model. Anesth Analg 2006;102:542-548.

47 Solevåg AL, Dannevig I, Wyckoff M, Saugstad OD, Nakstad B: Extended series of cardiac compressions during CPR in a swine model of perinatal asphyxia. Resuscitation 2010;81: 1571-1576.

48 Solevåg AL, Dannevig I, Wyckoff M, Saugstad OD, Nakstad B: Return of spontaneous circulation with a compression:ventilation ratio of 15:2 versus $3: 1$ in newborn pigs with cardiac arrest due to asphyxia. Arch Dis Child Fetal Neonatal Ed 2011;96:F417-F421.

49 Sobotka KS, Polglase GR, Schmölzer GM, Davis PG, Klingenberg C, Hooper SB: Effects of chest compressions on cardiovascular and cerebral haemodynamics in asphyxiated nearterm lambs. Pediatr Res 2015;78:395-400.

50 Perlman JM, Wyllie J, Kattwinkel J, Atkins DL, Chameides L, Goldsmith JP, et al: Part 11: Neonatal resuscitation: 2010 International Consensus on Cardiopulmonary Resuscitation and Emergency Cardiovascular Care Science with Treatment Recommendations. Circulation 2010;122:S516-S538.

51 Perondi MB, Reis AG, Paiva EF, Nadkarni VM, Berg RA: A comparison of high-dose and standard-dose epinephrine in children with cardiac arrest. N Engl J Med 2004;350:17221730 .
52 Patterson MD, Boenning DA, Klein BL, Fuchs S, Smith KM, Hegenbarth MA, et al: The use of high-dose epinephrine for patients with out-of-hospital cardiopulmonary arrest refractory to prehospital interventions. Pediatr Emerg Care 2005;21:227-237.

53 Crespo SG, Schoffstall JM, Fuhs LR, Spivey $\mathrm{WH}$ : Comparison of two doses of endotracheal epinephrine in a cardiac arrest model. Ann Emerg Med 1991;20:230-234.

54 Roberts JR, Greenberg MI, Knaub MA, Kendrick ZV, Baskin SI: Blood levels following intravenous and endotracheal epinephrine administration. JACEP 1979;8:53-56.

55 Jasani MS, Nadkarni VM, Finkelstein MS, Mandell GA, Salzman SK, Norman ME: Effects of different techniques of endotracheal epinephrine administration in pediatric porcine hypoxic-hypercarbic cardiopulmonary arrest. Crit Care Med 1994;22:1174-1180.

56 Mielke LL, Lanzinger MJ, Aschke C, Entholzner EK, Wilhelm MG, Henke J, et al: Plasma epinephrine levels after epinephrine administration using different tracheal administration techniques in an adult CPR porcine model. Resuscitation 2001;50:103-108.

57 Jankov RP, Asztalos EV, Skidmore MB: Favourable neurological outcomes following delivery room cardiopulmonary resuscitation of infants $<$ or $=750 \mathrm{~g}$ at birth. J Paediatr Child Health 2000;36:19-22.

58 Barber CA, Wyckoff MH: Randomized Controlled Trial of Endotracheal versus Intravenous Administration of Epinephrine during Neonatal Cardiopulmonary Resuscitation in Asphyxiated Piglets. Honolulu, Pediatric Academic Societies, 2008. E-PAS2008:4453.12.

59 Wyckoff $\mathrm{MH}$ : Neonatal cardiopulmonary resuscitation: critical hemodynamics. NeoReviews 2010;11:e123-e129.

60 Wyckoff MH, Wyllie J: Endotracheal delivery of medications during neonatal resuscitation. Clin Perinatol 2006;33:153-160, ix.

61 Doglioni N, Chiandetti L, Trevisanuto D: Intramuscolar epinephrine during neonatal resuscitation. Resuscitation 2015;90:e5.

62 Ellemunter H, Simma B, Trawoger R, Maurer $\mathrm{H}$ : Intraosseous lines in preterm and full term neonates. Arch Dis Child Fetal Neonatal Ed 1999;80:F74-F75.

63 Kleinman ME, Oh W, Stonestreet BS: Comparison of intravenous and endotracheal epinephrine during cardiopulmonary resuscitation in newborn piglets. Crit Care Med 1999; 27:2748-2754.
64 Abe KK, Blum GT, Yamamoto LG: Intraosseous is faster and easier than umbilical venous catheterization in newborn emergency vascular access models. Am J Emerg Med 2000;18: 126-129.

65 Lindner KH, Strohmenger HU, Ensinger H, Hetzel WD, Ahnefeld FW, Georgieff M: Stress hormone response during and after cardiopulmonary resuscitation. Anesthesiology 1992;77:662-668.

66 Wenzel V, Krismer AC, Arntz HR, Sitter H, Stadlbauer KH, Lindner KH, et al: A comparison of vasopressin and epinephrine for outof-hospital cardiopulmonary resuscitation. $\mathrm{N}$ Engl J Med 2004;350:105-113.

67 Gueugniaud PY, David JS, Chanzy E, Hubert H, Dubien PY, Mauriaucourt P, et al: Vasopressin and epinephrine vs. epinephrine alone in cardiopulmonary resuscitation. N Engl J Med 2008;359:21-30.

68 Mukoyama T, Kinoshita K, Nagao K, Tanjoh $\mathrm{K}$ : Reduced effectiveness of vasopressin in repeated doses for patients undergoing prolonged cardiopulmonary resuscitation. Resuscitation 2009;80:755-761.

69 Duncan JM, Meaney P, Simpson P, Berg RA, Nadkarni V, Schexnayder S, et al: Vasopressin for in-hospital pediatric cardiac arrest: results from the American Heart Association $\mathrm{Na}$ tional Registry of Cardiopulmonary Resuscitation. Pediatr Crit Care Med 2009;10:191195.

70 Gervais HW, Schleien CL, Koehler RC, Berkowitz ID, Shaffner DH, Traystman RJ: Effect of adrenergic drugs on cerebral blood flow, metabolism, and evoked potentials after delayed cardiopulmonary resuscitation in dogs. Stroke 1991;22:1554-1561.

71 Frontanes A, Garcia-Fragoso L, Garcia I, Rivera J, Valcarcel M: Outcome of very-lowbirth-weight infants who received epinephrine in the delivery room. Resuscitation 2011; 82:427-430.

72 Bada H: Prevention of intracranial hemorrhage. NeoReviews 200;1:5.

73 Sinclair JC, Bracken MB: Effective care of the newborn infant. Oxford, Oxford University Press, 1992.

74 Iacovidou N, Vasileiou PV, Papalois A, Syggelou A, Bassareo PP, Xanthos T: Drugs in newborn resuscitation: the more we learn the least we use. Curr Med Chem 2012;19:46064616. 